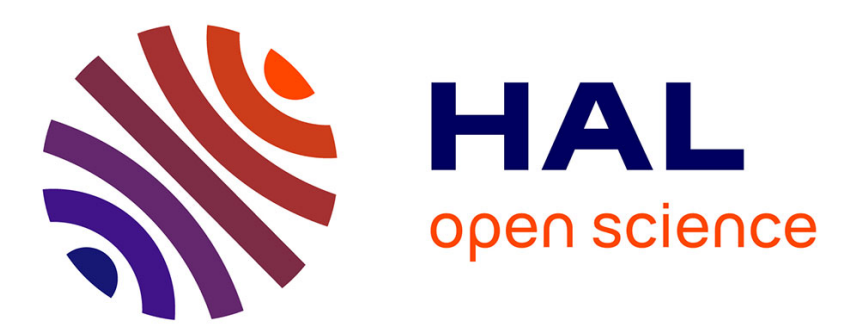

\title{
beta-C(sp2)-H Alkylation of enamides using xanthate chemistry
}

Sylvain Bertho, Ismaël Dondasse, Pascal Retailleau, Cyril Nicolas, Isabelle

Gillaizeau

\section{- To cite this version:}

Sylvain Bertho, Ismaël Dondasse, Pascal Retailleau, Cyril Nicolas, Isabelle Gillaizeau. beta$\mathrm{C}(\mathrm{sp} 2)-\mathrm{H}$ Alkylation of enamides using xanthate chemistry. New Journal of Chemistry, 2020, 10.1039/D0NJ01209B . hal-02990031

\section{HAL Id: hal-02990031 \\ https://hal.science/hal-02990031}

Submitted on 5 Nov 2020

HAL is a multi-disciplinary open access archive for the deposit and dissemination of scientific research documents, whether they are published or not. The documents may come from teaching and research institutions in France or abroad, or from public or private research centers.
L'archive ouverte pluridisciplinaire HAL, est destinée au dépôt et à la diffusion de documents scientifiques de niveau recherche, publiés ou non, émanant des établissements d'enseignement et de recherche français ou étrangers, des laboratoires publics ou privés. 


\title{
$\beta-C(s p 2)-H$ Alkylation of enamides using xanthate chemistry
}

\author{
Sylvain Bertho, ${ }^{\mathrm{a}}$ Ismaël Dondasse, ${ }^{\mathrm{a}}$ Pascal Retailleau, ${ }^{\mathrm{b}}$ Cyril Nicolas, ${ }^{\mathrm{a}}$ and Isabelle Gillaizeau*a
}

Received 00th January 20xx,

Accepted 00th January 20xx

DOI: $10.1039 / \times 0 \times x 00000 x$

An access to the $\gamma$-amino- $\beta, \gamma$-unsaturated acyl scaffold was developed by applying xanthate chemistry to enamides. This original $\beta-\mathrm{C}(\mathrm{sp2})-\mathrm{H}$ alkylation is regioselective and exhibits broad substrate scope and good functional group tolerance. The large availability of xanthates is advantageous to the scope of the reaction which combines a radical process and a polar reaction.

\section{Introduction}

Due to the importance of electron-rich $\mathrm{C}(\mathrm{sp} 3)-\mathrm{H}$ bonds found in many biologically active natural products and pharmaceuticals, ${ }^{1}$ the development of methods that allow the coupling of sp3 centers represents a great challenge in organic synthesis. Recent advances have permitted significant progress in sp3-sp2 cross coupling particularly in those involving single-electron pathways. ${ }^{2,3}$

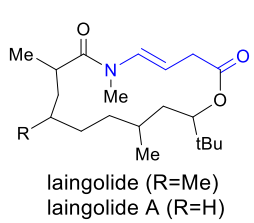


laingolide $A(R=H)$

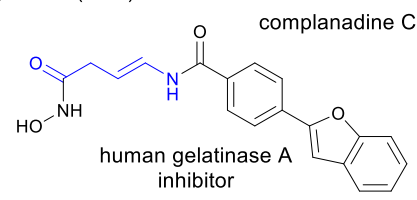

Figure 1. Representative bioactive compounds containing the $\gamma$-amino- $\beta, \gamma-$ unsaturated acyl scaffold.

The $\beta-\mathrm{C}(\mathrm{sp} 2)-\mathrm{H}$ alkylation of electron-rich olefins such as enamides has attracted particular attention, as the $\gamma$-amino- $\beta, \gamma$ unsaturated acyl moiety is a unique structural framework of biological interest and a polyvalent building block that can be

a. Institute of Organic and Analytical Chemistry, ICOA UMR 7311 CNRS, Université d'Orléans, rue de Chartres, 45100 Orléans, France.

E-mail: Isabelle.gillaizeau@univ-orleans.fr.

b. Institut de Chimie des Substances Naturelles, CNRS, 91198 Gif-sur-Yvette Cedex, France.

Electronic Supplementary Information (ESI) available: [details of any supplementary information available should be included here]. See DOI: $10.1039 / \mathrm{x} 0 \mathrm{xx} 00000 \mathrm{x}$ readily derivatized under a variety of conditions (Figure 1). ${ }^{4}$ As a result, a series of interesting methods on the direct intermolecular $\beta-\mathrm{C}(\mathrm{sp} 2)-\mathrm{H}$ alkylation of enamides has been reported (Scheme 1). ${ }^{3 a-b, 5}$ Most of them were triggered by the addition of an alkyl radical which is mainly generated by direct radical initiation ${ }^{6}$ or a single electron-transfer (SET) process. Renaud and Schubert studied the stereocontrolled addition of sulfonylmethyl radicals to chiral enamines followed by $\mathrm{H}$-atom transfers (path. (a)). ${ }^{7}$ Curran et al. described the addition of methyl malononitrile radicals to $N$-vinylpyrrolidinones as part of a broader study of phenylselenenyl group transfer additions to electron-rich alkene acceptors. ${ }^{8}$ Friestad reported an unusual non-reductive coupling of $N$-vinyloxazolidinones with $\alpha$ haloesters and iodoacetonitrile in presence of tri- $n$ butylstannane and AIBN as radical precursor. ${ }^{6}$ Visible-light iridium photoredox-catalysis was highlighted by $\mathrm{Yu}$ and coworkers using electron-deficient bromides as alkylating agents (path. (b)). ${ }^{9}$

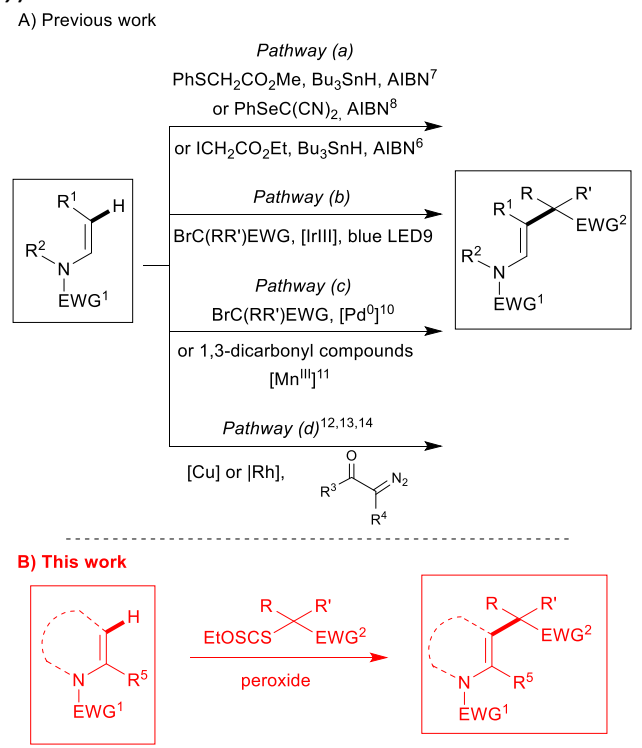

Scheme 1. Strategies for direct intermolecular $\beta-\mathrm{C}(\mathrm{sp} 2)-\mathrm{H}$ alkylation of enamide and access to the $\gamma$-amino- $\beta, \gamma$-unsaturated systems. 
Loh's group elegantly described a palladium-catalyzed strategy for the branch-selective alkylation of enamides (path. (c)). ${ }^{10} \mathrm{Li}$ and co-workers developed an efficient $\mathrm{Mn}^{\text {III-mediated cross }}$ dehydrogenation coupling reaction between enamides and 1,3dicarbonyl compounds. ${ }^{11}$ Another approach involved $\alpha$-diazo compounds as reported by Maas and Muller ${ }^{12}$ or Yan ${ }^{13}$ through a Cu"-catalyzed process and more recently upon $\mathrm{Rh}^{\text {"l-catalysis }}$ by Musaev and France. ${ }^{5 b}$ Although some of these methods show high efficiency and good functional group tolerance, there is still great room for improvement with the perspective of developing an efficient, generally applicable method.

Complementarily, xanthates ${ }^{14}$ have emerged as attractive feedstocks in radical coupling reactions and in promoting the direct alkylation of olefins, as elegantly developed by Zard, ${ }^{15}$ Miranda ${ }^{16}$ or Landais. ${ }^{17}$ It has been demonstrated that xanthates display an inherent advantage in the oxidative radical substitution of het(aryl) compounds. Zard reported the C-2 alkylation of $t$-butyl 3 -indolecarboxylate ${ }^{15 a}$ using such a strategy. The oxidative direct intermolecular alkylation of several heteroaromatic systems (i.e. indoles, pyrroles, furans, and thiophenes) was observed by Miranda. ${ }^{16 \mathrm{~b}}$ Furthermore, the same group demonstrated that xanthate-based radical chemistry could be used for the intermolecular alkylation of 1,3dimethyluracil. ${ }^{16}$ Of particular interest, the addition of a radical species derived from xanthate was highlighted by Zard on azetines, ${ }^{15 b}$ also once on the $N$-vinylpyrolidone ${ }^{15 c}$, and by Landais $^{17}$ in the carbo-alkenylation of enamides. Apart from these examples, and to the best of our knowledge, no study has showcased to date the applicability of xanthate in the direct intermolecular $\mathrm{C}(\mathrm{sp} 2)-\mathrm{H}$ alkylation of various enamides. Following our interest in radical processes to promote the selective functionalization of nitrogen-containing heterocycles, we report here the application of xanthate chemistry to the $\beta$ $\mathrm{C}(\mathrm{sp} 2)-\mathrm{H}$ alkylation of a range of non-aromatic enamides to synthesize new $\gamma$-amino- $\beta, \gamma$-unsaturated systems which are envisioned to be useful for further elaboration.

\section{Results and discussion}

At the outset of our study, we chose the commercially available $N$-vinylpyrrolidinone $1 \mathbf{a}$ and xanthate of ethyl acetate $\mathbf{2 a}$ as the coupling partner for our model reaction (Table 1). By applying Zard's guidelines, ${ }^{15}$ we began the optimization conditions by performing the reaction with enamide 1a (1 equiv.) and 2a (2 equiv.) in 1,2-dichloroethane (1,2-DCE) using readily biodegradable lauroyl peroxide (DLP, 1.2 equiv.) as the radical precursor. The reaction mixture was refluxed until the starting material 1a had been consumed (TLC monitoring). The related $\gamma$-amino- $\beta, \gamma$-unsaturated ester 3a was obtained in good yield (e.g., $62 \%$, entry 1 ) after $4 \mathrm{~h} 30$. The $E$ geometry of 3a was assigned on the basis of NMR data. ${ }^{18}$ Other radical initiators such as di-tert-butyl peroxide (DTBP), azobisisobutyronitrile (AIBN), iodobenzene diacetate or tert-butyl hydroperoxide were next studied. In most instances, the reaction did not proceed or a dramatic decrease in yield was observed (entries $2-5)$. The yield of 3a was also affected by the stoichiometry of the xanthate derivative (entries 6-7) and the amount of DLP (entries 8-9), demonstrating that 2 equiv. of 2 and 1.2 equiv. of DLP was mandatory. The decomposition half-life for a given radical precursor at an operating temperature is often of great significance. Lastly, portionwise (a portion every $90 \mathrm{~min}$ ) addition of the DLP initiator was compared with its addition in a single portion (entry 10). As expected, the direct addition of DLP proved to be the optimum choice. Polar effects in radical mediated processes are much less important than in ionic processes, allowing a much wider choice of solvents. The next step was therefore to screen common solvents for radical reactions. Of note, less polar aprotic solvents such as 1,4dioxane (entry 11) or the bio-renewable 2-Me-THF (entry 12) were capable of performing the transformation, albeit with lower efficiencies, whereas with ethyl acetate (entry 13) the addition proceeded well and product $3 \mathbf{3}$ was isolated with the same yield as previously observed with 1,2-DCE. We avoided using 1,2-DCE for environmental reasons. Acetonitrile proved less effective (44\%, entry 14 ). In addition, it is noteworthy that degradation was observed when conventional heating was replaced by microwave heating.

Table 1. Optimization of the $\beta-C(s p 2)-H$ alkylation of enamide $1 \mathbf{a}$ using xanthate $\mathbf{2 a}$.

\begin{tabular}{|c|c|c|c|c|}
\hline \multirow[b]{2}{*}{ Entry } & $\stackrel{\mathrm{EtO}_{2} \mathrm{C}}{L_{S}}$ & \multicolumn{2}{|c|}{$\begin{array}{c}\begin{array}{c}\text { Radical initiator } \\
(\mathrm{x} \text { eq. })\end{array} \\
\stackrel{\begin{array}{c}\text { solvent, reflux } \\
4 \mathrm{~h} 30\end{array}}{\mathrm{~h} 30}\end{array}$} & $3 \mathbf{a}$ \\
\hline & $\begin{array}{l}\text { Radical } \\
\text { initiator }\end{array}$ & Equiv. & Solvent & $\begin{array}{c}\text { Yield [\%] } \\
\text { of } 3 a^{b}\end{array}$ \\
\hline 1 & DLP & 1.2 & 1,2-DCE & 62 \\
\hline 2 & DTBP & 1.2 & 1,2-DCE & 0 \\
\hline 3 & AIBN & 1.2 & 1,2-DCE & 0 \\
\hline 4 & $\mathrm{Phl}(\mathrm{OAc})_{2}$ & 1.2 & 1,2-DCE & 10 \\
\hline 5 & $t-\mathrm{BuOOH}[5 \mathrm{M}]$ & 1.2 & 1,2-DCE & 0 \\
\hline $6^{c}$ & DLP & 1.2 & AcOEt & 58 \\
\hline $7^{d}$ & DLP & 1.2 & AcOEt & 62 \\
\hline 8 & DLP & 0.5 & 1,2-DCE & 30 \\
\hline 9 & DLP & 1 & 1,2-DCE & 50 \\
\hline $10^{\mathrm{e}}$ & DLP & 1.2 & 1,2-DCE & 35 \\
\hline 11 & DLP & 1.2 & 1,4-Dioxane & 32 \\
\hline 12 & DLP & 1.2 & 2-Me-THF & 31 \\
\hline 13 & DLP & 1.2 & AcOEt & 62 \\
\hline 14 & DLP & 1.2 & $\mathrm{MeCN}$ & 44 \\
\hline
\end{tabular}

a Typical reaction conditions: Argon-free oxygen atmosphere, compound 1a (56 $\mathrm{mg}, 1$ equiv.), xanthate $\mathbf{2 a}$ ( 2 equiv.), radical initiator (1.2 equiv.), solvent (1.5 $\mathrm{mL}$ ), heating under reflux for $4 \mathrm{~h} 30 .{ }^{\mathrm{b}}$ Isolated yield after purification by column chromatography ( $\mathrm{SiO}_{2}$, petroleum ether/EtOAc). ${ }^{\mathrm{c}} 1.5$ equiv. of xanthate $2 \mathrm{a}$ was used. ${ }^{d} 2.5$ equiv. of xanthate $2 \mathrm{a}$ was used. ${ }^{\mathrm{e}} \mathrm{A}$ portion ( 0.4 equiv.) of the radical initiator was added every $90 \mathrm{~min}$.

On the basis of literature precedent, the following mechanism can be proposed (Figure 2). The thermal decomposition of lauroyl peroxide (DLP) initiates first the radical addition of enamide $\mathbf{1}$ by the alkyl radical $\mathbf{A}$ to provide the amido radical $\mathbf{B}$. As observed with (het)aromatic systems and the uracil system, ${ }^{16}$ lauroyl peroxide induces the oxidation of the latter into the corresponding cation $\mathbf{C}$ and its resonance structure $\mathbf{D}$. A proton elimination generated the enamide $\mathbf{3}$. The transfer-xanthate 
product resulting from the trapping of the amido radical $\mathbf{B}$ by the xanthate was not observed. However, in some specific cases with more electron-rich enamides, the iminium species $\mathbf{D}$ can be trapped by a nucleophile (i.e. the released carboxylate $\mathrm{C}_{11} \mathrm{H}_{23} \mathrm{CO}_{2}^{-}$) leading to the difunctionalized adduct 4 , isolated as a mixture of cis-trans diastereoisomers. This mechanism demonstrated the need for a stoechiometric amount of lauryl peroxide for the reaction to succeed.

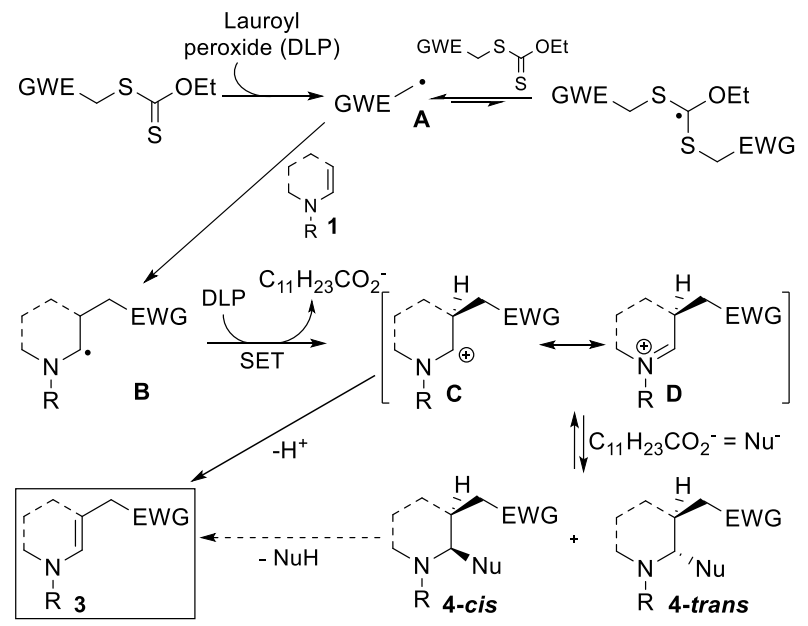

Figure 2. Proposed mechanism.

With the optimized conditions in hand, we next examined the $\beta-\mathrm{C}(\mathrm{sp} 2)-\mathrm{H}$ alkylation of various enamides $\mathbf{1 a - q}$ with $\mathbf{2 a}$ (Scheme 2). To our delight, a series of cyclic and acyclic enamides 1 were successfully converted to the corresponding $\beta$-alkylated enamides 3. Monosubstituted 5- or 7-membered ring tertiary enamides $\mathbf{1} \mathbf{a}-\mathbf{b}$ worked well, giving the new alkylated product $\mathbf{3 a} \mathbf{a}-\mathbf{b}$ as a unique $E$ stereoisomer. ${ }^{18}$ The secondary enamide 1c was also suitable for this alkylation reaction and provided $3 \mathrm{c}$ in good yield. Cyclic (i.e. 6- or 7membered rings) di-substituted enamides $\mathbf{1} \mathbf{d}-\mathbf{i}$ bearing various electron-withdrawing $N$-protecting groups were also good substrates in this reaction and led to the desired alkylated products $\mathbf{3 d}-\mathbf{i}$ with moderate to good yields. It is worth noting that the corresponding ene-sulfonamide proved not to be activated enough to react. The alkylation of $\mathbf{3} \mathbf{j}$ bearing an ester group at the C-2 position, which could serve as a valuable synthetic intermediate was tolerated. Furthermore, the reaction turned out to be compatible with other functional groups such as a hydroxyl group (3k), which was amenable to further useful transformations. Notably, the vinylogous $\beta$ alkylester enamide $\mathbf{3 l}$ and pyridones $\mathbf{3} \mathbf{m}-\mathbf{n}$ were isolated in moderate yields accompanied, in the case of $3 \mathrm{~m}$, with unreacted starting material. It is noteworthy that functionalized pyridones are useful partners in Diels-Alder cycloadditions. ${ }^{19}$ Interestingly, no chemoselectivity was observed starting from the $N$-allyl enamide 10; a xanthate transfer was indeed additionally observed onto the allylic olefin allowing the implementation of a potential second radical sequence (30). The observed low yields are due mainly to a slight degradation of the reaction mixture. As previously observed by us, ${ }^{20}$ when more electron-rich enamides were used, the di-functionalized morpholin-2-ones $\mathbf{4 p - q}$ were originally isolated as a cis:trans isomer mixture (1:1 ratio). In this case, we assume that no elimination step occurred as the electron donor property of the oxygen atom lowers the acidity of the nearby proton in $\mathbf{4 p - q}$. The latter two examples illustrate in an interesting way the oxyalkylation reaction of enamides. ${ }^{21}$

$$
\text { (1) }
$$
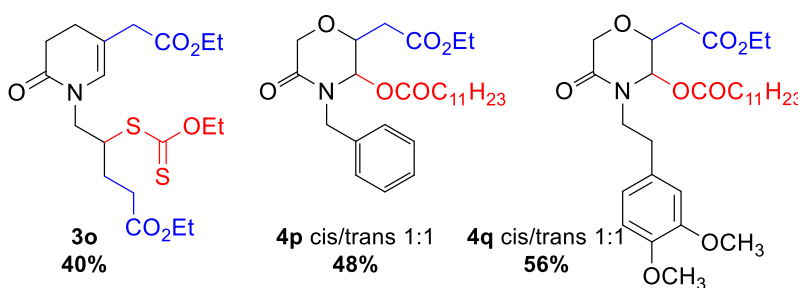
Scheme 2. $\beta-C(s p 2)-H$ Alkylation of diverse enamides 1a-q using xanthate 2a xanthate $2 a$ ( 2 equiv.), DLP (1.2 equiv). AcOEt, heating under reflux for $4 \mathrm{~h} 30$. brsm: based on recovered starting material.

To ascertain the scope of this reaction, various xanthates $\mathbf{2} \mathbf{b}$ f (Scheme 3) were prepared by substitution of the corresponding halo derivative with commercially available potassium ethyl xanthogenate. ${ }^{22}$ Remarkably, a variety of electron-deficient primary and secondary alkyl groups successfully underwent this transformation to give a range of new substituted acyclic enamides 3ab-af bearing an $\gamma$-ester or $\gamma$-nitrile function in moderate to good yields (39-72\%).

With the objective of increasing the molecular diversity, and based on the proposed mechanism depicted in Figure 2, we next envisaged that a nucleophile introduced into the reaction mixture could be trapped by the iminium species of type $\mathbf{D}$ (Figure 2), leading to enamides 5 in good yields. Intra- and 
intermolecular processes can be envisioned (Scheme 4, (a) and (b)). The tandem difunctionalization of enamides involving the simultaneous formation of $\mathrm{C}(\mathrm{sp} 3)-\mathrm{C}(\mathrm{sp} 3)$ and $\mathrm{C}-\mathrm{O}$ or $\mathrm{C}-\mathrm{CN}$ bonds has proven to be a powerful tool for the synthesis of various motifs. ${ }^{23,24 a}$ Firstly, starting from 5- or 7-membered exocyclic enamides $\mathbf{1} \mathbf{a}-\mathbf{b}$ and through a sequential one-pot reaction, 10 equivalents of ethanol or phenol were used to intermolecularly trap the iminium ion intermediate leading to $\mathbf{5 a}-\mathbf{h}$ in good yields. In addition to this oxyalkylation reaction, cyanoalkylation was observed using TMSCN as the nucleophile. ${ }^{24}$

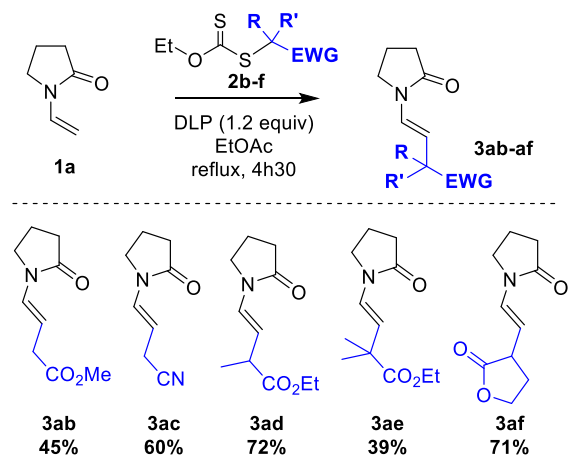

Scheme 3. Alkylation reactions of enamide $\mathbf{1 a}$ with diverse xanthates $\mathbf{2 b}-\mathbf{f}$ Reaction conditions: Argon-free oxygen atmosphere, enamide 1a (1 equiv., 0.33 M), xanthate $\mathbf{2 b - f}$ ( 2 equiv.), DLP (1.2 equiv.), AcOEt, heating under reflux for $4 \mathrm{~h} 30$.

A large array of transformations can thus be envisaged to introduce further diversity and complexity into the structures. Starting from the enamide 1s bearing a chain with a pendant dimethoxyphenyl group as the nucleophile, spontaneous cyclization occurred, leading directly to the new tricyclic enamide $5 \mathbf{i}$ with an overall yield of $30 \%$ for the three-step sequence. As the limiting step is the intramolecular addition of the nucleophilic aryl moiety onto the iminium ion intermediate, conducting the reaction in the absence of ethanol resulted in the degradation of the reaction mixture. Additionally, a twostep sequence can be achieved by taking advantage of the iminium ion intermediate reactivity in acidic media (Scheme 4 , (c)) from $4 r$ allowing the formation of the original tricyclic and diversely substituted morpholine derivative $\mathbf{5 j}$. The compound 5j was isolated as a unique trans diastereoisomer; The relative stereochemistry was unambiguously confirmed by X-ray crystallography. ${ }^{25}$ Furthermore, the $\gamma$-ester function in the enamide $3 \mathrm{~h}$ was reduced with good yields in the corresponding primary alcohol 6 in presence of $\mathrm{LiAlH}_{4}$. This approach thus illustrated the potential of this strategy to provide access to a wide range of nitrogen containing heterocycles decorated with various functional groups.
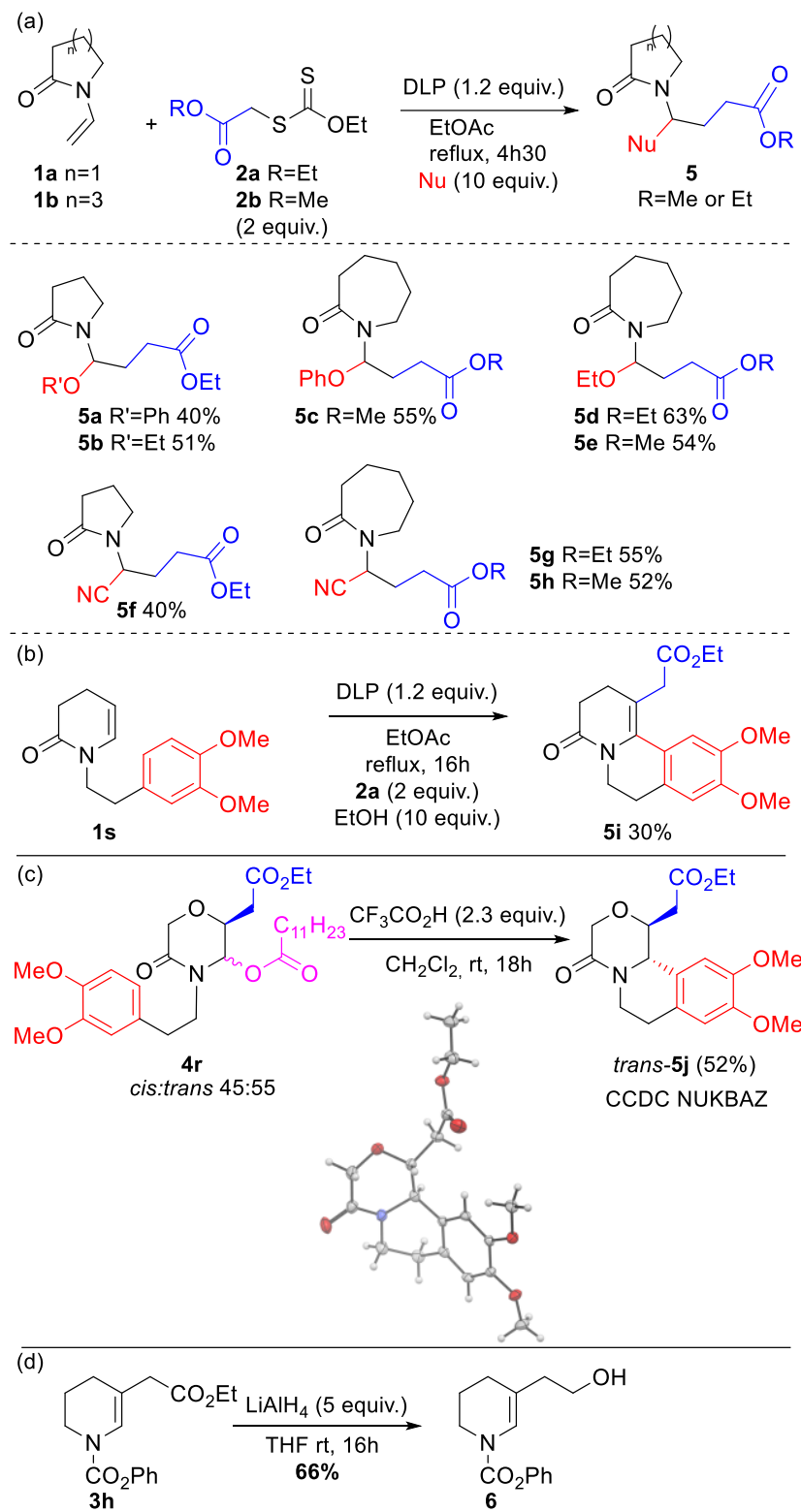

Scheme 4. (a) and (b) Difunctionalization of enamide $\mathbf{1 a}$ or $\mathbf{1 b}$ with xanthate $\mathbf{2 a}$ or $\mathbf{2 b}$ in presence of nucleophiles. Reaction conditions: Argon-free oxygen atmosphere, enamide $\mathbf{1} \mathbf{a}$ or $\mathbf{1} \mathbf{b}$ ( 1 equiv., $0.33 \mathrm{M}$ ), xanthate $\mathbf{2} \mathbf{a}$ or $\mathbf{2 b}$ ( 2 equiv.), DLP (1.2 equiv.), related nucleophile (10 equiv.), AcOEt, heating under reflux for $4 \mathrm{~h} 30$ to $18 \mathrm{~h}$. (c) Cyclization of $\mathbf{4 r}$ to $\mathbf{5 j}$ in presence of trifluoroacetic acid. Ortep view of the crystal structure $\mathbf{5 j}$ (CCDC NUKBAZ). Displacement ellipsoids are drawn the $30 \%$ probability level and hydrogen atoms with an arbitrary radius size. (d) Reduction of the $\gamma$-amino- $\beta, \gamma$-unsaturated ester $\mathbf{3 h}$ to the primary alcohol 6.

\section{Conclusions}

In summary, we have developed a mild, simple and efficient access to the $\gamma$-amino- $\beta, \gamma$-unsaturated acyl scaffold by applying xanthate chemistry to enamide. This original reaction is totally regioselective and exhibits broad substrate scope, good functional group tolerance and thus demonstrates its potent application in the synthesis of versatile $N$-containing building blocks. The large availability of xanthates is advantageous to the scope of the reaction which combines a radical process and a 
polar reaction. Further applications based on this chemistry are in progress in our laboratory.

\section{Experimental}

\section{General information}

Unless otherwise noted, all reagents and solvents were purchased from commercial sources and used as received. All manipulations were conducted under argon. The reactions were monitored by thin-layer chromatography (TLC) using silica gel (60 F254) plates. Compounds were visualized using a UV lamp $(254 \mathrm{~nm})$ and/or by potassium permanganate stain. Flash column chromatography was carried out on silica gel 60 (230400 mesh, 0.040-0.063 mm). Melting points ( $\mathrm{mp}\left[{ }^{\circ} \mathrm{C}\right]$ ) were taken on samples in open capillary tubes and are uncorrected. The infrared spectra of compounds were recorded on a Thermo Scientific Nicolet iS10. ${ }^{1} \mathrm{H},{ }^{13} \mathrm{C}$ and ${ }^{19} \mathrm{~F}$ NMR spectra were recorded on a spectrometer at $250 \mathrm{MHz}\left({ }^{13} \mathrm{C}, 62.9 \mathrm{MHz}\right)$ or 400 $\mathrm{MHz}\left({ }^{13} \mathrm{C}, 100 \mathrm{MHz} ;{ }^{19} \mathrm{~F}: 376 \mathrm{MHz} \mathrm{CPD}\right)$. High-resolution accurate mass measurements (HRAM) were recorded with a Maxis Bruker $4 \mathrm{G}$ instrument and were performed in positive mode with an ESI source on a Q-TOF mass spectrometer with an accuracy tolerance of $2 \mathrm{ppm}$ by the "Fédération de Recherche" ICOA/CBM (FR2708) platform.

General Procedure for the Synthesis of Enamides 1d-i, 1k, 1 I and 10-1q (G.P. A). An oven-dried single-necked roundbottomed flask under argon atmosphere was charged with dry toluene, the related imide 1 ( 1.0 equiv., $0.49 \mathrm{M}$ ) and a magnetic stir bar. The reaction vessel was cooled to $-78{ }^{\circ} \mathrm{C}$ (dry ice/acetone bath) and a $1 \mathrm{~m}$ solution of $\mathrm{LiEt}_{3} \mathrm{BH}$ in THF (1.1 equiv.) was then added dropwise. The mixture was stirred further at $-78{ }^{\circ} \mathrm{C}$ for $1 \mathrm{~h}$. Next, $\mathrm{N}, \mathrm{N}$-Diisopropylethylamine (DIPEA, 5.7 equiv.) and a catalytic amount of 4Dimethylaminopyridine (DMAP, 0.03 equiv.) were added, followed by the dropwise addition of Trifluoroacetic anhydride (TFAA, 1.2 equiv.) and the reaction mixture was allowed to warm up to room temperature (ca. $20^{\circ} \mathrm{C}$ ). The mixture was stirred for $3 \mathrm{~h}$ at the same temperature and it was quenched by the addition of water. The aqueous phase was then extracted twice with EtOAc, combined organic phases were washed (sat. aq. $\mathrm{NaCl}$ ), dried over $\mathrm{MgSO}_{4}$ and filtered through a cotton plug. The solvents were evaporated under reduced pressure and the resulting crude enamide derivative was purified by column chromatography $\left(\mathrm{SiO}_{2}\right)$.

General Procedure for the Direct Oxidative Radical $\beta-C(s p 2)-H$ Monoalkylation of Enamides (G.P. B). An oven-dried 2-5 mL microwave vial under argon atmosphere was charged with the enamide substrate (1.0 equiv., $0.33 \mathrm{M})$, ethyl acetate, corresponding xanthate ( 2.0 equiv., $0.66 \mathrm{M}$ ) and a magnetic stir bar. The solution was degassed 3 times (vacuum/argon cycles), the reaction vessel was capped and it was placed in a preheated oil bath for $5 \mathrm{~min}$ at $90^{\circ} \mathrm{C}$. Next, the vial was uncapped and dilauroyl peroxide (DLP, 1.2 equiv.) was added. The vessel was sealed and the reaction mixture was heated at $78^{\circ} \mathrm{C}$ for 4.5 h under argon atmosphere. After cooling to $\mathrm{rt}$ (ca. $20^{\circ} \mathrm{C}$ ), the solvent was concentrated under reduced pressure. The residue was taken up in dichloromethane and dry silica was added (approximately 10 times the mass of the sample). The solvents were evaporated in vacuo until the silica is dry and free-flowing and the coated support was packed on top of a silica gel column. The crude product was purified $\left(\mathrm{SiO}_{2}\right)$ to give the desired monoalkylated enamide derivative in moderate to good yield.

General Procedure for the Radical Difunctionalisation of Enamides With Xanthates in Presence of a Nucleophile (G.P. C). An oven-dried 2-5 mL microwave vial under argon atmosphere was charged with the enamide substrate (1.0 equiv., $0.33 \mathrm{M})$, related xanthate derivative ( 2.0 equiv., $0.66 \mathrm{M}$ ), ethyl acetate and a magnetic stir bar. The solution was degassed 3 times (vacuum/argon cycles), the reaction vessel was capped and it was placed in a pre-heated oil bath for $5 \mathrm{~min}$ at $90{ }^{\circ} \mathrm{C}$. Next, the vial was uncapped and DLP (1.2 equiv.) followed by corresponding nucleophile (10 equiv.) were added. The vessel was sealed and the reaction mixture was heated at $78^{\circ} \mathrm{C}$ for 4.5 $\mathrm{h}$ under argon atmosphere. After cooling to $\mathrm{rt}$ (ca. $20^{\circ} \mathrm{C}$ ), the solvent was concentrated under reduced pressure. The residue was taken up in dichloromethane and dry silica was added (approximately 10 times the mass of the sample). The solvents were evaporated in vacuo until the silica is dry and free-flowing and the coated support was packed on top of a silica gel column. The crude product was purified $\left(\mathrm{SiO}_{2}\right)$ to give the desired dialkylated enamide compound in moderate to good yield.

General procedure D (G.P. D). Alternatively, after solvent concentration in G.P. B and G.P. C, addition of cold acetonitrile could be performed at $0{ }^{\circ} \mathrm{C}$, leaving decomposition products from DLP undissolved. The precipitate was filtered through a sintered glass Büchner funnel and the mother liquor was recovered. Then, the acetonitrile was removed by rotary evaporation and the product residue was purified further by flash $\mathrm{SiO}_{2}$-column chromatography.

\section{Conflicts of interest}

There are no conflicts of interest to declare.

\section{Acknowledgements}

The authors thank the Labex SynOrg ANR-11-LABX-0029 and the Region Centre-Val de Loire for financial support and fellowships (S.B., I.D.).

\section{Notes and references}

1 a) F. Lovering, J. Bikker and C. Humblet, J. Med. Chem., 2009, 52,6752; b) F. Lovering, MedChemComm, 2013, 4, 515.

2 a) R. Jana, T. P. Pathak and M. S. Sigman, Chem. Rev., 2011, 111, 1417; b) S. Z. Tasker, E. A. Standley and T. F. Jamison, Nature, 2014, 509, 299; c) M. R. Netherton and G. C. Fu, Adv. Synth. Catal., 2004, 346, 1525; d) A. Rudolph and M. Lautens, Angew. Chem., Int. Ed., 2009, 48, 2656; e) C. E. Knappke, S. 
Grupe, D. Gartner, M. Corpet, C. Gosmini and A. Jacobi von Wangelin, Chem. Eur. J., 2014, 20, 6828; f) M. Iwasaki, N. Miki, Y. Ikemoto, Y. Ura and Y. Nishihara, Org. Lett., 2018, 20, 3848, g) K. Zhu, J. Dunne, M. P. Shaver and S. P. Thomas, ACS Catal., 2017, 7, 2353.

3 a) R. Rey-Rodriguez, P. Retailleau, P. Bonnet and I. Gillaizeau Chem. Eur. J., 2015, 21, 3572; b) G. Caillot, J. Dufour, M.-C. Belhomme, T. Poisson, L. Grimaud, X. Pannecoucke and I. Gillaizeau, Chem. Commun., 2014, 50, 5887; c) I. Fabre, T. Poisson, X. Pannecoucke, I. Gillaizeau, I. Ciofini and L. Grimaud, Catal. Sci. Tech., 2017, 7, 1921.

4 a) S. Chansakaow, T. Ishikawa, H. Seki, K. Sekine, M. Okada and C. Chaichantipyuth, J. Nat. Prod., 2000, 63, 173; b) K Ishiuchi, T. Kubota, Y. Mikami, Y. Obara, N. Nakahata and J. Kobayashi, Bioorg. Med. Chem., 2007, 15, 413; c) M. Ikura, S. Nakatani, S. Yamamoto, H. Habashita, T. Sugiura, K. Takahashi, K. Ogawa, H. Ohno, H. Nakai and M. Toda, Bioorg. Med. Chem., 2006, 14, 4241; d) H. Takayama, R. Fujiwara, Y. Kasai, M. Kitajima and N. Aimi, Org. Lett., 2003, 5, 2967; e) G. Pomey and P. Phansavath, Synthesis, 2015, 47, 1016; f) T. Anker, C. C. Cosner and P. Helquist, Chem. Eur. J., 2013, 19, 1858.

5 a) T. Zhu, S. Xie, P. Rojsitthisak and J. Wu, Org. Biomol. Chem., 2020, 18, 1504; b) B. D. McLarney, M. A. Cavitt, T. M. Donnell, D. G. Musaev and S. France, Chem. Eur. J., 2017, 23, 1129; c) J.-Y. Guo, Z.-Y. Zhang, T. Guan, L.-W. Mao, Q. Ban, K. Zhao and T.-P. Loh, Chem. Sci., 2019, 10, 8792.

6 G. K. Friestad and Y. Wu, Org. Lett., 2009, 11, 819.

7 P. Renaud and S. Schubert, Synlett, 1990, 624.

8 D. P. Curran, E. Eichenberger, M. Collis, M. G. Roepel and G. Thoma, J. Am. Chem. Soc., 1994, 116, 4279.

9 H. Jiang, C. Huang, J. Guo, C. Zeng, Y. Zhang and S. Yu, Chem. Eur. J., 2012, 18, 15158.

10 R. Ding, Z.-D. Huang, Z.-L. Liu, T.-X. Wang, Y.-H. Xu and T.-P. Loh, Chem. Commun., 2016, 52, 5617.

11 P. Li, J. Zhao, C. Xia and F. Li, Org. Lett., 2014, 16, 5992.

12 G. Mass and A. Mueller, J. Parkt. Chem., 1998, 340, 315.

13 a) W.-J. Zhao, M. Yan, D. Huang and S.-J. Ji, Tetrahedron, 2005, 61, 5585; b) M. Yan, W.-J. Zhao, D. Huang and S.-J. Ji, Tetrahedron Lett., 2004, 45, 6365

14 For reviews of the xanthate transfer chemistry, see: a) S. Z. Zard, Angew. Chem., Int. Ed. Engl., 1997, 36, 672; b) S. Z. Zard, In Radicals in Organic Synthesis; P. Renaud, M. P. Sibi, Eds; Wiley-VCH: Weinheim, 2001, Vol. 1, p 90; c) B. Quiclet-Sire and S. Z. Zard, Chem. Eur. J., 2006, 12, 6002; d) B. Quiclet-Sire and S. Z. Zard, Top. Curr. Chem., 2006, 264, 201; e) S. Z. Zard, Org. Biomol. Chem., 2007, 5, 205; f) S. Z. Zard Tetrahedron, 2020, 76, 130802.

15 a) B. Quiclet-Sire, G. Revol and S. Z. Zard, Org. Lett., 2009, 11, 3554; b) S. Han and S. Z. Zard, Org. Lett., 2014, 16, 1992; c) F. Gagosz and S. Z. Zard, Org. Lett., 2003, 5, 2655; d) N. Cholleton, I. Gauthier-Gillaizeau, Y. Six and S. Z. Zard, Chem. Comm., 2000, 535.

16 a) P. E. Reyes-Gutiérrez, R. O. Torres-Ochoa, R. Martínez and L. D. Miranda, Org. Biomol. Chem., 2009, 7, 1388; b) L. D. Miranda, E. Icelo-Ávila, A. Rentería-Gómez, M. Pila and J. G. Marrero, Eur. J. Org. Chem., 2015, 19, 4098; c) V. M. Pérez, D. Fregoso-López and L. D. Miranda, Tetrahedron Lett., 2017, 58, 1326.

17 C. Poitevin, V. Liautard, R. Beniazza, F. Robert and Y. Landais, Org. Lett., 2013, 15, 2814.

18 A trans coupling constant $J^{3}=14.6 \mathrm{~Hz}$ was observed on ${ }^{1} \mathrm{H}$ NMR.

19 See a recent review: F. Hao and N. Nishiwaki, Molecules, 2020, DOI:10.3390/molecules25030673.

20 S. Bertho, R. Rey-Rodriguez, C. Colas, P. Retailleau and I. Gillaizeau, Chem. Eur. J., 2017, 23, 17674.
21 a) R. Ding, W.-G. Lu, H. Ci, Y.-Y. Mao and L. Liu, ChemistrySelect, 2019, 4, 6954; b) T. Courant and G. Masson, Chem. Eur. J. 2012, 18, 423-427.

22 See the supporting information for details.

23 Q.-J. Liu, L. Wang, Q.-K. Kang, X. P. Zhang and Y. Tang, Angew. Chem. Int. Ed., 2016, 55, 9220.

24 a) G. Masson and G. Bernadat, Synlett, 2014, 2842; b) X.-Q. Chu, D. Ge, Z.-L. Shen and T.-P. Loh, ACS Catal., 2018, 8, 258.

25 CCDC NUKBAZ (5j) contains the supplementary crystallographic data for this paper. This data is provided free of charge by the Cambridge Crystallographic Data Centre 
COMMUNICATION 